\title{
Cross-cultural adaptation of reproductive health services in
} Bolivia

\author{
Fernando Gonzales Salguero \\ Population Council \\ Antonieta Martin \\ Population Council \\ Rosario Perez Mendoza \\ Population Council \\ Ricardo Vernon \\ Population Council
}

Follow this and additional works at: https://knowledgecommons.popcouncil.org/departments_sbsr-rh

Part of the Demography, Population, and Ecology Commons, Health Services Research Commons, and the International Public Health Commons

How does access to this work benefit you? Let us know!

\section{Recommended Citation}

Gonzales Salguero, Fernando, Antonieta Martin, Rosario Perez Mendoza, and Ricardo Vernon. 2005.

"Cross-cultural adaptation of reproductive health services in Bolivia," FRONTIERS Final Report.

Washington, DC: Population Council.

This Report is brought to you for free and open access by the Population Council. 


\title{
Cross-cultural Adaptation of Reproductive Health Services in Bolivia
}

\author{
Fernando Gonzales Salguero, Maria Antonieta Martín, \\ Rosario Pérez Mendoza, Ricardo Vernon \\ Population Council \\ Frontiers in Reproductive Health Program
}

September 2005

This study was funded by the UNITED STATES AGENCY FOR INTERNATIONAL DEVELOPMENT (USAID) under the terms of Cooperative Agreement Number HRNA-00-98-00012-00 and In-house Project Number 8000 13069. The opinions expressed herein are those of the authors and do not necessarily reflect the views of USAID. 


\section{SUMMARY}

Bolivia's indigenous peoples, who make up nearly 60 percent of the country's population, face cultural barriers in access to and use of health services. The Bolivian Ministry of Health and Sports (MOH) and the Integral Health Project (Proyecto de Salud Integral, PROSIN), with the technical assistance of the Population Council's Frontiers in Reproductive Health Program (FRONTIERS), tested several strategies to make health services in Bolivia more culturally appropriate.

This operations research project was developed in the municipality of Tinguipaya, in the department of Potosí. Tinguipaya is largely rural and has the lowest socio-economic and health indicators in the country. The majority (62\%) of the inhabitants of the municipality speaks only Quechua and maintain ancestral customs from the Inca period, including the communal ownership of land, social and economic organization, and techniques for farming. The municipality has 10 health facilities - one health center in the village of Tinguipaya (where $3 \%$ of the population lives), and nine health posts.

The goal of this project was to increase women's access to, use of, and satisfaction with health services in general, and reproductive health services in particular, by offering culturally appropriate health services. The project worked with health providers to: a) enhance the understanding and acceptance of the "other" culture; b) improve their communication skills; c) facilitate and promote their use of the Quechua language in clinics; d) systematically screen their clients' health service needs; and e) establish selfassessment and supervision mechanisms. The project also sought to promote communityprovider interactions by creating advisory committees for women to voice expectations of health care services, and by fostering interaction between traditional health providers and the modern system.

Methodologically it was a demonstration study with a non-experimental design, with measurements before and after the interventions. Qualitative information was collected from health providers, women in the community and traditional health providers as part of the initial diagnosis. This information provided a better understanding of the context in which the project was developed. Information was gathered regarding the beliefs and expectations clients have of services offered by health facilities.

The project's interventions had significant positive effects on the demand for reproductive health services: the demand for seven of the 21 reproductive health services available increased after the interventions, including the demand for contraception and consultations for sexually transmitted infections (STI).

The intervention to strengthen communication skills was enthusiastically implemented by the providers. The results show important changes in the client-provider interaction, especially the warmth with which clients were received, the use of non-verbal communication skills, and the socio-emotional content of the phrases employed. Greater participation by the clients and their husbands during consultations was also observed. 
Due to the low complexity of the intervention, its moderate cost and its acceptance, its replicability is feasible.

The use of the instrument for systematic screening of unmet reproductive health needs helped to significantly increase the average number of services provided per client from one to three. The instrument was used mainly by nurse auxiliaries, both in health facilities and during their visits to communities. Given the evidence provided by recent studies on the usefulness of this strategy, the use of systematic screening should be promoted on a larger scale.

Training and reference materials were also produced as part of this project, which are available for use in other programs. The $\mathrm{MOH}$ has expressed interest in integrating them into its intercultural strategy. These materials include: a) a module on the Andean world view, containing a description of traditional knowledge and practices related to reproductive health; b) culturally appropriate protocols that incorporate elements of the Andean culture in the delivery of reproductive health services; c) a glossary of Quechuan and popular terms to help health providers establish better communication with the Quechua clients; and d) a manual for implementing a strategy to improve the quality of the communication between providers and clients. 


\section{Table of Contents}

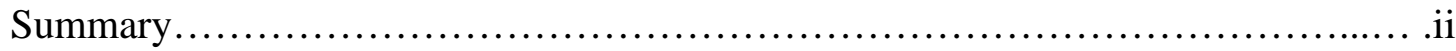

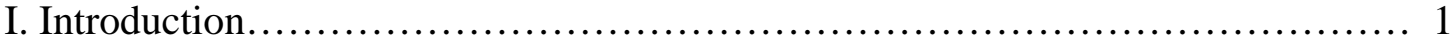

II. Problem Statement........................................................... 3

III. Objectives............................................................... 6

IV. Methodology......................................................... 7

V. Interventions Implemented............................................ 10

5.1 Developing Materials on Andean Health Culture..................... 10

5.2 Improving Communication Skills.................................... 11

5.3 Self-Assessment and Supervision.............................. 12

5.4 Systematic Screening of Health Needs............................... 13

5.5 Other Interventions to Link Providers with the Community............ 13

VI. Results............................................................ 14

6.1 Diagnostic Study..................................................

6.2 Changes in the Demand for Reproductive Health Services................21

6.3 Changes in Interpersonal Communication..............................25

6.4 Changes in the Systematic Screening of Health Needs...................27

VII. Conclusion............................................................ 28

VIII. Dissemination and Use............................................ 29

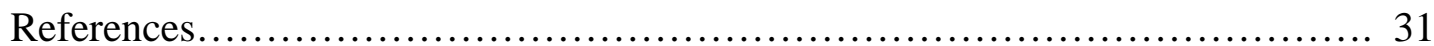




\section{INTRODUCTION}

Bolivia is both multiethnic and multicultural. According to the 2001 National Census, nearly 60 percent of the population is indigenous. Most belong to the Quechua, Aymará, or Guaraní cultures, but there are also smaller percentages of other ethnic groups.

Despite the improvements observed over the last few years in most health indicators (e.g., maternal and infant morality, births attended by trained personnel, prenatal care coverage), the health system still faces challenges. Among them is the persistent inequality between urban and rural areas (for example, the total fertility rate (TFR) is 3.1 children per woman in the urban area and 5.5 in the rural, whereas the infant mortality rate (IMR) is 44 and 67 per 1,000 live births, respectively), and between the indigenous and the Spanish-speaking populations. According to PAHO (2004), 22 percent of health care exclusion can be attributed to belonging to a specific ethnicity.

The government of Bolivia's Strategic Plan for the Reduction of Poverty (Plan Estratégico de Reducción de la Pobreza) includes among its main objectives "development with identity" and "the reduction of inequities and barriers entrenched in ethnic discrimination.” In the health sector, various official documents mirror the need to focus on cultural differences. For example, the first article of the Universal Maternal and Child Insurance Law (Ley de Seguro Universal Materno Infantil, SUMI 2002) indicates that "where appropriate, the benefits of the Universal Maternal and Child Health Insurance will be adapted and implemented through traditional Bolivian medicine, whenever the uses and customs of indigenous populations, farmers or natives to the area choose to.” The Program for Women's Health and Sexual and Reproductive Health Care 2003 - 2007 (Programa de Atención a la Salud de la Mujer y a la Salud Sexual y Reproductiva 2003 - 2007) also includes extensive descriptions that promote an integration of traditional and biomedical medicines (MOH 2003).

Despite these advances, a functional operations model has not been developed that adapts health services to their clients' culture. In 2003, the Ministry of Health and Sports (MOH) through its Integral Health Project (Proyecto de Salud Integral, PROSIN) requested technical assistance from the Population Council's Frontiers in Reproductive Health Program (FRONTIERS). The aim was to develop an operations research project to test solutions to the low health service coverage registered in rural areas in the Potosí department.

According to the 1998 DHS, Potosí department has a population of 756,000 inhabitants, with two-thirds living in rural areas (INE y DHS 1998). Nearly 80 percent of the population is of Quechua descent. Although half is mestiza (part indigenous, part Spanish-descent), approximately 27 percent speaks only Quechua, and the rest is bilingual in Spanish and Quechua. Traditions from the Inca period are still maintained in the rural area of Potosí, such as the communal ownership of land, organization by means 
of ayllus ${ }^{1}$ and ancestral farming techniques. According to the Municipal Health Index (MHI), which includes variables such as access to drinking water, the percentage of children with diarrhea, the proportion of births in health institutions, and infant mortality, Potosí Department has the worst health conditions in Bolivia (OPS 2001). The IMR is 81 per 1,000 live births. Approximately 20 percent of women of reproductive age have no formal schooling. The TFR is 5.2 children per woman, the second highest in the country after the department of Chuquisaca. Only 73 percent of women have heard of contraceptive methods, and only 12.4 percent of women use a modern contraceptive method (31.6\% use any method at all; rhythm is the most common). It is estimated that nearly 38 percent of women have unmet needs for contraception, the second highest rate in the country, also after Chuquisaca.

The use of health services in Potosí is also among the lowest in Bolivia. For example, one-third of pregnant women do not receive prenatal care; over two-thirds of children under the age of three have never been vaccinated, and 63 percent of births take place at home. This low use of services is frequently attributed to the high proportion of indigenous populations in the Potosí department and to the cultural barriers they face to access services.

The Tinguipaya municipality in Potosí was selected for this operations research project. Tinguipaya, with a population of 22,742 inhabitants is mainly rural, with only three percent of the population living in Tinguipaya village, the largest village in the municipality. It is located 70 kilometers from the city of Potosí (around 4 hours by car), and can be reached by a dirt road that is accessible throughout the year. Its topography comprises steep hills, high plateaus, and valleys. The weather is temperate and humid in the valleys, cold and dry in the plateaus.

Sixty-two percent of the population speaks only Quechua; this proportion is higher among women. The bilingual population (Spanish/Quechua) is 19 percent with the remainder speaking only Spanish or only Aymara. The inhabitants of the municipality are dedicated mainly to agricultural activities for family use. According to the National Statistics Institute, 97.6 percent of the population of the municipality lives in extreme poverty. Basic service coverage is extremely low: only 34 percent have access to potable water, only three percent have electricity, and there are no sewage systems (UDAPSO 1994).

The municipality has 10 health facilities - nine health posts and one health center. In seven of the posts, only one nurse auxiliary is responsible for the facility. In the other two, the posts are attended by a rotating medical intern and a nurse. The Tinguipaya health center has two doctors, two nurses, two nursing auxiliaries, and a dentist as well as

\footnotetext{
${ }^{1}$ The ayllu is an ancestral model of social and economic organization in Andean culture where the agrarian economic unit is the family; the extended consanguineous family constitutes the sayaña and the group of families or sayañas makes up the ayllu. A group of ayllus then makes a marca, which the Spaniards termed “community." In terms of functions, each unit has its own authority, norms for social coexistence, ways of using the land, and mutual services.
} 
a limited number of beds for inpatient services. Referrals are made directly to the Daniel Bracamonte Hospital in the city of Potosí.

In terms of reproductive health, 60 percent of pregnant women have at least one checkup. However, only 15 percent of pregnant women return to complete the four follow-up visits recommended by the Bolivian service delivery guidelines. Institutional births in Tinguipaya make up eight percent of expected births, whereas in the neighboring municipality of Yocalla they make up 40 percent. The number of women that use a contraceptive method is very low, considering that only 297 continuous users were reported by the health services in 2003 and there are 4,752 women of reproductive age in the municipality.

\section{PROBLEM STATEMENT}

The most frequent explanation for the low use of health services provided by health programs in Bolivia is the presence of intercultural barriers, which can be understood as the lack of understanding between two coexisting populations of different cultures. In the case of Bolivia, health services are typically organized and offered according to modern medical criteria and methods, but the clients for whom these services are designed have different beliefs, preferences, and criteria to cure their ailments, which originate in the ancient Andean culture.

Intercultural barriers are apparent in at least two areas: knowledge, attitudes and practices; and social relations between health providers (modern and traditional) and the population. Both modern medicine and Andean culture have developed their own rational systems that sustain their practices and knowledge. Both systems have coexisted for many years and coincide in recommendations that have a strong rational base, typical of each system, such as not lifting heavy objects, preventing the loss of blood during pregnancy, not getting upset during pregnancy or breastfeeding, and exclusive breastfeeding for newborns.

However, there are also many preferences and beliefs that stand between the two systems. This clash between beliefs is an obstacle when accessing health services. For example, indigenous families perceive childbirth to be a familiar and intimate act that should take place in warm and enclosed spaces. They prefer that the husband be the only person to attend the woman in labor, and that he carry out traditional rituals related to feeding and clothing the woman, and disposing of the placenta as tradition requires. However, maternity wards have transformed childbirth into an almost public act, where several strangers provide care, and women feel strange in cold and ventilated labor rooms, barely covered by a robe, and where the placenta is simply disposed of (Gonzales et al. 1991a; 1991b).

A second example of the clash between beliefs is how infection in the puerperal period (known in indigenous culture as sobreparto) is treated. Both systems agree upon its seriousness and the need for treatment. In the modern medical system, however, the 
origin is infectious and should be treated primarily with antibiotics. In the traditional Andean system, on the other hand, the origin is cold air and water, and it must be treated primarily through ritual. In neither case, then, does the health system meet the expectations, preferences, and psychological needs of its clients, who then distance themselves from formal services and seek solutions in traditional medicine.

In 1997 Project Concern International (PCI) designed a study to understand the intercultural barriers that had an effect on the results of its sexual and reproductive health program (FHI 1997). Research was carried out in rural zones in the departments of Potosí, Oruro, and Cochabamba, with a population that is mainly Quechua and to a lesser extent Aymará. This study found that health personnel frequently show excessive ethnocentrism in the communities, and that they look down on clients' explanations or concepts. For example, they rejected treatments that clients may have received before their visit; sometimes their behavior was so aggressive that the sick person and whoever accompanied him or her were thrown out because they admitted to having applied the advice of the local healer, or they carried out a ritual according to their customs. Some personnel consider traditional or popular health practices to be "practices of ignorance." In other words, there are no behaviors or common codes to ease communication, and therefore messages are neither understood and internalized, nor used as feedback.

The Project Concern study also reached various conclusions on the interaction between different actors that intervene in health care.

\section{Interactions between the individual, the family, and the health care system}

In the Andean context, individuals are considered a simple component of a larger group. Their attitudes and practices lead them to behave in ways that are not solitary. In this sense, the family is the basic unit, and the community is the ideal group. This aspect is of particular importance to explain sickness in terms of the disintegration of the group and of family conflict, and also explains the tendency of the entire family accompanying the sick person when he or she is checked into a hospital. Therefore, if the individual's balance is broken within the cultural context (i.e., family, community, environment), a conflict is created (e.g., fear, anguish, loss of spirit), and disease appears. Sickness does not manifest itself only in the individual, but also in the family group, which must be the object of attention. In contrast with the individual attention given in health facilities, traditional healers generate a dynamic in which both the sick person and his or her family receive a shared benefit. When the sick person heals, the family also heals in a metaphorical sense. As a result, in the context of Andean reciprocity, family and community strengthen the role of the healer, developed entirely within the communitarian cultural context, and the healer fortifies the cohesion of the community.

It should also be pointed out that healers and people in general interpret sickness as "someone" or "something" attacking to produce the disease (for example, earth, a Godfather, or a"a bad smell”). This personalization explains many of the ritual actions that take place both in the diagnosis as well as the cure for the disease. 


\section{Interaction between the modern medical and the traditional health system}

Although there is not much information available on the relationship between traditional and modern medical health providers, it is evident their interactions are marked by unfortunate behaviors on both sides. For example, at one time many physicians tried to take traditional healers to trial, accusing them of the illegal practice of medicine. On the other hand, traditional healers frequently spread rumors about alleged negative actions within health facilities; they emphasize the excessive youthfulness or inexperience of personnel and let people know that coca leaf readings have indicated the incapacity of health service providers.

The community's traditional structures respond to the conceptual and ideological reality of its inhabitants. By not recognizing their functionality or their organization, health service providers provoke a logical response of defensiveness among healers and the community. Also by manifesting their own ethnocentrism, they undermine their relationships with the social structure and their position within the community.

\section{Knowledge, attitudes and practices related to sexuality and reproduction in Bolivia's Andean communities}

Several studies in anthropology, public health, and medical anthropology (PCI 1996; 1997; Gonzales et al. 1991a; 1991b) show that women tend to talk little about their sexual lives. Although women know that fertilization occurs through the union of the man's sperm with a fluid from the woman, and that this process occurs in the uterus, the majority does not know exactly how to avoid an unwanted pregnancy. Some women have heard of pills and injections, but they do not know where to get them or how they work. Abortion is seen as a way of limiting family size; the most frequent motive for it seems to be the difficulty of supporting one more child, rather than a reaction to social sanctions against single or young mothers.

Menstruation is known as a period (regla) or a "custom" (costumbre). The most typical idea is that it is "bad" or "dirty" blood that must be eliminated from the body so that it doesn't accumulate. Some women consider many discomforts (such as headaches and abdominal pains) to be related to the fact that blood is not expelled when it should be. It is usual that during the premenstrual and menstrual periods, women drink hot mate (tea), avoid air currents and water. During these days they also wear more clothing than usual in order not to get cold.

Fertility is a central element for women's self-esteem, and therefore any practice that could prevent a woman's getting pregnant is rejected. Men choose the woman who will be their partner and decide when to have sexual relations. There is apparently very little willingness for women to regulate their fertility, since this could be a reason for other men to mock them.

Based on similar findings in other studies, PCI developed culturally appropriate protocols for contraceptive orientation. A few examples of these protocols are the following: 
- Always ask the woman if she wants her partner to also receive the information; carry out the activity with the partner inasmuch as possible, since this decreases the possibility that the husband will disapprove of any decision made by the woman.

- Be very cautious when asking about the couple's sexual life. It is better to use popular terms that describe intercourse: be together, sleep together, to be with her husband.

- Be very discreet when asking details about the couple. It is important to remember that, especially in the mining zones, a great proportion of partners are temporary, and both women and men can change partners every so often.

- Care should be taken in using certain terms that are usually employed but that among rural populations have a double meaning. A Quechua woman will find it inappropriate to be asked about her compañero or "companion" when referring to her husband or partner, since she will understand it as a reference to her husband's penis, which gives the question a pejorative, insulting, and insolent sense when coming from a stranger.

- Values having to do with fertility and knowledge about menstruation and fertilization should be taken into account when explaining the effects of contraceptives.

- Take into account immaterial contextual aspects, such as the care that women take to not expose themselves to the cold, or to touch water when they are menstruating. Asking a woman to undress under these circumstances could be damaging for the interaction.

In conclusion, a revision of scientific literature and programmatic documents shows that intercultural elements are a significant barrier for the increase in the indigenous population's use of health services. The problem lies in the fact that service providers and inhabitants of rural communities have different sets of beliefs and values, and there is a certain mutual "looking down" on the "other" culture, as well as an inability to speak, even in cases where they need each other.

\section{OBJECTIVES}

The overall objective of this project was to make health services more culturally appropriate, thereby increasing women's access to, use of, and satisfaction with health services in general and reproductive health services in particular.

The specific objectives were the following: 
- To improve service providers' interpersonal and intercultural communication skills and practices, especially with indigenous clients. To achieve this objective, the project provided training for providers in order to: enhance their understanding and acceptance of the "other" culture; improve their communication skills; and facilitate and promote their use of the Quechua language in clinics.

- To develop a self-assessment tool for providers' interpersonal and intercultural skills; establish a supervision mechanism; and foster the continuous learning of providers.

- To help providers become more sensitive to clients' unexpressed service needs through systematic screening.

- To promote community-provider interactions by creating advisory committees for women to voice expectations of health care services, and by fostering interaction between traditional health providers and the modern system.

\section{Hypotheses}

As a consequence of the activities implemented by the project:

1. There will be an increased demand for reproductive health services in participating health posts and facilities.

2. There will be a larger proportion of consultations in which client needs are systematically reviewed.

3. There will be higher quality of care in client-provider interaction.

4. There will be greater client satisfaction with the services provided.

All relevant audiences were involved in this project from the beginning of the activities. The project was jointly created by PROSIN, SEDES Potosí and the Tinguipaya Municipality authorities. Coordination agreements were also established with the Network Direction, Italian Cooperation (COPITAL), Cooperazione Internazionale (COOPI), The Information Analysis Committee (Departmental CAI), and with other health organizations that work in the Potosí department.

\section{METHODOLOGY}

The study had a simple before and after design. To assist in project design, a baseline diagnostic study was conducted to document existing perceptions about health services and cultural barriers to access and use. The first activity in the project was a situational analysis of the conditions in Tinguipaya's communities and health services. As part of the 
diagnosis, all 10 of the municipality's health facilities were visited. The physical conditions, availability of equipment, supplies, and human resources were noted, as well as accessibility characteristics.

Data were collected through client-provider observations and exit interviews with clients, interviews with providers, focus groups with women of reproductive age in the catchment areas of the facility, and interviews with traditional healers. The diagnostic study was conducted in March 2004. Qualitative data proceeding from focal groups and qualitative interviews were treated using the qualitative analysis technique described in The Handbook for Excellence in Focus Group Research (Debus 1995).

\section{Study Sample}

The sample for this study consisted of 15 service providers (five doctors, two licensed nurses and eight nurse auxiliaries) from the 10 health facilities. Before the intervention there were 14 providers. Fifteen providers were trained in the intervention. There were 46 observed consultations (23 pre- and 23 post-intervention) among the providers.

\section{Testing Hypotheses}

To measure the demand for reproductive health services in order to test hypothesis one, data were collected from facility service statistics on: the number of reproductive health service clients (by service: prenatal, postpartum, pap smear); the number of clients that received contraceptive counseling; and the number of women who are new users of contraceptive methods. Each facility reports these activities to the National System for Health Information (Sistema Nacional de Información en Salud, or SNIS), the source of all service statistics in the country. Service statistics from April to December in 2003 and the corresponding months in 2004 were compared using the least squares method and the t-test. Before comparing the difference between means for each variable, the Levene test was performed for equality of variances. The Levene test allows us to determine whether there was homogeneity of variance in both periods. The analysis was made using monthly data.

To measure whether the intervention resulted in a larger proportion of clients screened for needed services (hypothesis two), the observed consultations were audio taped and the tapes analyzed to determine the proportion of consultations in which the provider investigated other reproductive and sexual health needs. In addition, information obtained in the client exit interviews was analyzed to note when a client reported that this activity was carried out. Responses indicative of screening were coded as one, and the rest of the answer options as zero.

To measure the extent to which quality of care in client-provider interactions improved as a result of the intervention (hypothesis three), verbal communication was analyzed. The audiotapes of the client-provider observations were translated, transcribed, and then analyzed using the Roter Interaction Analysis System (RIAS) which assigns one of 57 unique codes to each utterance (i.e., word, phrase, or sentence) according to their 
meaning within the context of the consultation (Roter 1995; 1997). RIAS was developed originally to study client-provider interaction in family planning consultations. Both the remarks of the provider and client are coded and then grouped into either medical (diagnostic and therapeutic) or socio-emotional content. The frequency of each code was compared in the pre- and post-intervention periods.

Medical communication is established to determine the diagnosis and provide information on therapeutic aspects to be followed by the client. It includes behaviors such as asking open-ended versus closed questions, requesting medical information, checking if the information has been understood, and encouraging the client to provide more information. Examples of the codes are: uses non-medical language; provides medical information; asks open-ended questions on medical condition; informs client about the therapeutic regime; checks if client has understood; and expresses concern.

Socio-emotional communication has the purpose of establishing a climate of mutual trust that allows open exchange of information to facilitate the client's participation, make decisions based on her personal needs, and understanding and following medical recommendations according to the client's specific situation. Communicating in an open fashion facilitates the interaction, particularly when the provider asks questions on lifestyles and psychosocial aspects; shows interest and approval, establishes a relationship of mutual trust, expresses positive emotions, approves and shares or shows concern for the client's expressions. Some examples of the codes include: gives instructions; shares personal experience; congratulates the client; makes an alliance for decision-making; and tells the client he or she can ask questions at any moment.

Non-verbal communication was studied with the help of a checklist that detailed different non-verbal behaviors during the consultation. Non-verbal communication among service providers and clients has an impact on quality of care, for example welcoming the person with a kind gesture or a smile, offering a seat, looking into her eyes, and caring for privacy. During the consultation, the provider was observed to see if he or she was paying attention, s/he was in a hurry or seemed annoyed, if body posture showed interest, if the tone of the voice showed superiority. The client is observed to see if she expressed confidence, if she sat at ease, if she maintained visual contact with the provider, and if her face suggested a lack of understanding related to what the provider is saying. Responses indicative of positive non-verbal communication were coded as one, and the rest of the answer options as zero.

Exit interviews with clients were also used to measure client satisfaction (hypothesis four). Researchers examined: the proportion of women that said they were satisfied with the service delivered; the proportion of women who evaluated different elements of service delivery and provider treatment positively; and the proportion of women that felt confident enough to ask questions about their reproductive health during the counseling visit. Information obtained in exit interviews was transcribed to a database. To determine quality of care, responses indicative of quality were coded as one, and the rest of the answer options as zero. The points were added to create a scale, and the range was 
divided into three grades: low, medium and high. The data were analyzed with SPSS in order to find statistical differences between pre and post-intervention interviews.

\section{INTERVENTIONS IMPLEMENTED}

To solve these problems, interventions were tested, seeking to improve the interaction between clients and providers in order to achieve greater respect and mutual understanding, by training providers on local beliefs so they understand the specific needs of clients. The following activities were implemented to improve the clientprovider interaction:

\subsection{Developing Materials on Andean Health Culture}

\section{Workshop on Andean Cultural Elements}

In order to improve service providers' interpersonal and intercultural communication skills and practices, the project provided training for providers in the form of a three-day workshop which focused on Andean cultural elements. As mentioned earlier, the Andean cultural view has many elements related to the processes of health/sickness, individual/society, family/traditional health provider, and sexuality. Health service providers usually challenge these beliefs, which is one of the reasons why the population does not approach the services. In this project we consider health providers would be more respectful of the indigenous world view if they understood its basic cognitive elements. This knowledge would allow them to communicate more easily, within a reference frame used by their clients.

All health personnel in the Tinguipaya municipality attended the workshop (specifically 18 persons, including doctors, nurses, a dentist and nurse auxiliaries), as well as technical and administrative personnel from PROSIN and SEDES. A researcher, physician, and an anthropologist were in charge of training, using the PCI research cited earlier (Velasco 1997a; 1997b). Among the subjects studied were the following:

- Andean health and sickness concepts: the metaphor of equilibrium, sickness, and its causes from a cultural point of view.

- Notions of ethno-anatomy: the metaphor of the body, the earth and the mountain; traditional names for parts of the body; and anatomic elements related to sexuality and reproduction.

- Notions of ethno-physiology: the functions of reproduction; the concept of masculine and feminine and its representation in nature; and myths and taboos around pregnancy. 
- Customs related to health: possibilities of their deployment in educational activities as models of interpretation; and the use of different Andean metaphors in reproductive health service counseling.

- The role of the healer or traditional doctor: an analysis of elements of success in the context of families; and employing the elements analyzed in order to adapt the role of health personnel in their reproductive health service activities.

\section{Andean world view module and culturally appropriate protocols}

The project also developed a document that served as a text for training and as a reference for health providers. This document, the Andean World View Module, included what was presented in the workshop, the results of a bibliographic revision, the results of the initial diagnostic studies, and the personal experiences of the authors. To complement the module, the project also created a document with specific recommendations for providing health services to indigenous populations, based on the Andean World View Module. These culturally adapted protocols to provide reproductive health services were validated in collaboration with health providers and women from the communities.

\subsection{Improving Communication Skills}

\section{The Appropriate Use of the Quechua Language}

To improve the communication skills of providers, and to facilitate and promote their use of the Quechua language in clinics, a glossary was compiled of Quechua terms, phrases, and ideas used to talk about sexuality and reproduction. Except for one physician, all providers in the intervention area used Quechua to attend clients who spoke the language, yet several providers said they were unsure of the appropriate Quechua terms for naming parts of the body, contraceptive methods, and reproductive functions.

The compilation of the terms and their meanings was validated through a process of successive interviews with health personnel, groups of women from the communities, doctors, traditional midwives, and professional experts on the subject. In order to widen the potential use of the glossary, and taking into account that some Quechua terminology differs from place to place, the terms were also validated in two periurban neighborhoods in the city of Potosí. The glossary was compiled by the local research coordinator in Potosí, who required the support of a bilingual interviewer, a linguist and the nurse from the Potosí Network Direction.

\section{Interpersonal Skills}

In addition to knowing the Andean cultural vision and the language, interpersonal skills for communication are very important. There are values that are almost universal to allow appropriate communication with others, such as knowing how to listen, inform, interview, and show respect for the other people and their ideas. Twenty-five health providers and several PROSIN representatives attended a workshop in Potosí to 
strengthen their interpersonal skills. The workshop focused on six communication skills: listening, informing, interviewing, responding to the needs of the client, stimulating the client's participation, and expressing positive emotions. Each skill has a corresponding set of behaviors that the provider has to practice in order to improve the skill, for example looking at the client when she speaks, asking open-ended questions, and listening to the answers and concerns of the client. The training included an adapted version of the Hablemos en Confianza [Let's talk confidentially] manual and videos to illustrate some of the skills that must be put into practice (Poppe et al 1999; Martin 2004).

\subsection{Self-Assessment and Supervision}

\section{Self-Assessment}

The project also developed a self-assessment tool for providers' interpersonal and intercultural skills, and established a supervision mechanism. Both of these interventions were aimed at fostering the continuous learning of providers.

To continue to strengthen their communication skills, providers were trained to follow a self-assessment process by audio taping consultations with clients, by listening to the taped consultations, and filling out self-assessment questionnaires about their interactions with clients. Providers were instructed to request client consent to tape consultations in order to start the self-assessment process.

Workshop participants were provided with: six brochures entitled "Hojas Saber Cómo" (Know-How Sheets) - one for each of the communication skills mentioned above, which portray positive and negative examples of what should and should not be done during the visit; a tape recorder and batteries; and a supply of self-assessment forms to use when they listened to the audio-taped consultations.

\section{Supervision}

To achieve permanent behavior change, providers need to receive periodic feedback and focus their attention on the change they are striving for. Monthly supervision visits to the providers took place. During her visits, the supervisor verified advances in interpersonal communication skills (e.g., listening, asking, informing, responding to client needs, stimulating client participation, and expressing positive emotions). She listened to previously taped consultations by providers, gave them feedback, and provided motivation for them to continue with self-assessments.

For the nurse auxiliaries, the self-assessment process was complicated in terms of reading so many questions, understanding them, and filling out each questionnaire for each skill they were practicing. On the other hand, though the male physicians had no problem reading the self-assessment forms, they were reluctant to audiotape their consultations and make self-assessments. 
The supervisors (the project coordinator and the project monitor) also attended the monthly meetings held by service providers to analyze service statistics. In these meetings of the information analysis committee, an average of two hours were dedicated to reviewing project advances.

\subsection{Systematic Screening of Health Needs}

Health services frequently respond only to the needs expressed by their clients, and leaving aside other services that the client may need or desire but either does not know she can request them in the same visit, or does not know these services exist. An essential aspect of a proper service is that it should respond to clients' needs, not only their most urgent, but also additional health needs, including preventive medicine. To address this, the project also provided training to help providers become more sensitive to clients' unexpressed service needs through systematic screening, defined as the proactive offer of additional services during client visits (Foreit, Hardee, and Agarwal 2002).

Systematic screening is the use of an instrument to identify the client's needs and desires for health services. Screening is done with either a simple checklist or a slightly more elaborate questionnaire. The identified services are then offered to the client at the same or subsequent visit or through a referral. The ultimate goal of systematic screening is to reduce unmet health service needs among program clients. Several studies have shown that systematic screening allows an increase in coverage at a lower cost than providing only the individual services requested by clients (Foreit et al. 2005; Vernon and Foreit 1999; Das et al. 2005; León et al. 1998; Sanogo et al. 2005).

Training in systematic screening was also presented during the one-day workshop. Health providers adapted and used systematic screening instruments in order to learn how to systematically screen for and attend the reproductive health needs of clients in health facilities or in communities.

\subsection{Other Interventions to Link Providers with the Community}

In addition to the interventions described above, the study tested two strategies for establishing linkages between providers and communities.

The first was the creation of an advisory committee of community women that were to meet periodically (at least once a month) with service providers from each participating health center to talk about what they liked and did not like about the way in which health services were offered, and make recommendations to improve them. However, the time available for the implementation of the project (8 months) was too short for organizing the groups and fostering changes in the attitudes of women, many of whom took on a passive role and expected their participation to be rewarded in some way.

To foster interaction between traditional health providers and the modern system, the project created a directory of traditional health service providers in the communities, invited them to periodic meetings to discuss strategies to coordinate activities, and invited 
them to provide consultations in the health center. The problem with this activity was their geographic dispersion, an aspect that made it difficult to attend the meetings programmed in some of the communities. The one meeting where it was possible to conduct in-depth interviews was one called by the Italian Cooperation Aid Assistance that brought vehicles to transport traditional physicians from their communities to the meeting place. This project did not have the resources for transportation, and asking the traditional providers to attend meetings from remote locations by their own means simply did not work. For this reason, only two midwives and two traditional doctors participated.

As implementing these activities was difficult and was only partially done, results from the initial diagnostic study are presented, as well as service statistics and qualitative data from follow-up interviews and observations with selected providers and clients.

\section{RESULTS}

\subsection{Diagnostic Study}

Results of the diagnostic study, including the situation analysis of the health facilities, are presented below.

\section{Characteristics of Service Delivery Outlets}

The municipality has a medical director who is in charge of health services and periodically meets with and visits different providers to supervise and attend to their needs. As in the rest of the country, the Universal Maternal and Child Insurance pays for all services provided to pregnant women, women with children under 6 months old, and children under the age of five years. Medicines have to be paid for in all other services.

All ten health facilities in the municipal network have potable water and a radio for communication. Only two have electricity, and only the Tinguipaya health center has telephone access. Although there are roads to all health facilities, only four of them can be reached with vehicles in the dry season, so they are isolated for around five months every year. Many clients walk long distances to reach the health facilities, and the personnel have to walk many kilometers to have access to transportation. Half of these health facilities have a motorcycle to visit small settlements that are far from the services and for transport when there are emergencies.

In the areas of the health facilities there are traditional birth attendants and healers as well as active community groups. The health facilities try to establish relationships with them in order to implement community health actions. Table 1 shows the number of health workers that were identified in the municipality and the number that collaborate with the formal health system along with observations on the active community groups. 
Table 1. Identifying community health personnel

\begin{tabular}{|l|l|l|}
\hline Type of community personnel & $\begin{array}{l}\text { Existing } \\
\text { Number }\end{array}$ & $\begin{array}{l}\text { Number that collaborate with health } \\
\text { services/Observations }\end{array}$ \\
\hline Traditional birth attendants & 14 & $\begin{array}{l}\text { 2 maintain relationships with health } \\
\text { providers }\end{array}$ \\
\hline Community health volunteers & 12 & $\begin{array}{l}\text { They all report to the health facility in their } \\
\text { area }\end{array}$ \\
\hline $\begin{array}{l}\text { Traditional doctors } \\
\text { (healers or curanderos) }\end{array}$ & 23 & $\begin{array}{l}\text { 4 maintain relationships with health } \\
\text { providers }\end{array}$ \\
\hline Organized groups of women & 7 & Literacy groups formed by CARITAS \\
\hline Other community groups & 10 & Agrarian syndicates, formed mainly by men \\
\hline
\end{tabular}

Services offered: the following services are available in the municipal health facilities:

- In all facilities: prenatal care; birth care; postpartum care; counseling; family planning; integrated care for children under 5-years; immunizations; educational talks; and home visits.

- In eight health facilities: STI/HIV/AIDS counseling. The two remaining facilities do not offer this service because providers are not trained.

- In two health facilities: Pap smears.

- In the Tinguipaya health center: dentistry and basic laboratory work.

The situation analysis showed differences across facilities. Table 2 presents the availability of contraceptive methods. 
Table 2. Availability of contraceptive methods in the Tinguipaya municipality health network

\begin{tabular}{|l|c|l|}
\hline $\begin{array}{l}\text { Contraceptive } \\
\text { Method }\end{array}$ & $\begin{array}{l}\text { Number of health } \\
\text { facilities where they } \\
\text { are available }\end{array}$ & $\begin{array}{l}\text { Number of health facilities where } \\
\text { they are not available/Observations }\end{array}$ \\
\hline LAM & 5 & $\begin{array}{l}\text { Unavailable in 5 facilities due to lack of } \\
\text { provider training }\end{array}$ \\
\hline Rhythm method & 7 & $\begin{array}{l}\text { Unavailable in 3 facilities due to lack of } \\
\text { provider training }\end{array}$ \\
\hline Standard Days Method & 2 & $\begin{array}{l}\text { Unavailable due to lack of provider } \\
\text { training and because providers think } \\
\text { they need the bead necklace to provide } \\
\text { the method }\end{array}$ \\
\hline Male Condon & 10 & $\begin{array}{l}\text { Although 8 facilities have IUDs, only } \\
\text { doctors are trained and authorized to } \\
\text { insert them. Only 2 facilities have the } \\
\text { complete insertion equipment. }\end{array}$ \\
\hline Depo-Provera & 10 & \multicolumn{2}{|l}{} \\
\hline Pill & 10 & \\
\hline IUD & 2 & \\
& \multicolumn{2}{|l}{}
\end{tabular}

None of the health facilities currently have either the required supplies to take Pap smear samples or have clinical histories of non-pregnant women.

While all health facilities have contraceptive method samplers, other IEC material on reproductive health is scarce. Only two health facilities also had flipcharts and a video and TV set. No other training or information material was available.

\section{Quick Assessment of the Quality of Interpersonal Communication}

From the diagnostic study, client-provider observations and exit-interviews with clients showed that there is good communication between providers and clients, and providers have a positive attitude during consultations. However, there is room to improve communication skills and provide more comprehensive health care by systematically screening clients for their reproductive health needs. Although many believe that women do not like to speak to providers about personal issues, women showed that they wanted to do so. Providers have to foster this socio-emotional communication to obtain more commitment from clients to care for their health, and for the acceptance and continuous use of contraceptive methods.

In general, doctors dedicate more time to technical topics during interaction with clients, whereas nurses and nurse auxiliaries use more familiar language. However, paramedic personnel need to reinforce their technical knowledge and abilities to counsel clients. 
Contrary to what was expected, women do not want to have more children and are interested in family planning services. Service providers should therefore give more information to clients and support them in their decision-making process, even when the husband is not present. Only two nurses out of six observed that providers talked about contraceptive methods. One of the nurses introduced the family planning theme when a client was complaining about backaches and headaches because she had too many children. The other nurse introduced contraceptive use with two clients who visited the health services for well-child consultation. She used the contraceptive method chart to explain their characteristics. However, the nurse missed the opportunity to help one client with decision-making and to provide her with a contraceptive method, when that client expressed that she wanted to know more about oral contraceptives or injectibles and which one was good for her. In general, it appears that providers suggest the use of contraceptive methods in the future, not during the present consultation. Providers suggest that the client talk about it with her husband and if possible, come back with him to make the final decision, indicating this decision is to be made in the future.

\section{Interviews with providers}

Providers indicated there was very low demand for sexual and reproductive health services and preventive services in general. Most consultations are for sick children or adults with general ailments. The vaccination program and well baby and child care are more successful.

On the other hand, providers seem to have little knowledge of and lack supplies to offer reproductive health services. Some are embarrassed or find it very difficult to talk about sexuality and reproduction, and most offer contraceptive services only to couples; they are afraid to provide women with contraceptives when the husband is not there, because husbands make decisions about family planning; however, this is also changing.

When providers say they offer services taking into account the clients' culture, they mean elements such as language, rituals, respect for intimacy that is expressed by "not touching much,” and making references to traditional healers. It was also observed that they include elements such as not scolding clients for lack of hygiene and their clothes. Some providers have participated in traditional cures to heal their own health problems.

All service providers interviewed knew traditional doctors in their communities. Most had interacted with them and established informal referral and counter referral mechanisms. The main obstacle to establishing a formal working relationship seems to be that traditional healers often demand recognition or monetary payments for services.

With regard to the idea of forming groups of women that could advise the health facilities, providers said that there were no organized groups in the communities. Most ideas tend to be talked about with the men and the community authorities, who provide their consent. Although providers accepted that a group of women could advise health personnel, they tended to think of them as receptors, not providers of training or other kinds of benefits or services. The greatest obstacle perceived by providers for 
implementing this strategy was having an incentive, since women would not attend meetings if they received nothing in exchange. They expected some sort of gift, such as food or clothing, or learning a craft, such as knitting or embroidery.

\section{Focus groups with women}

Three focus groups were held with married Quechua women of reproductive age who were residents of the Tinguipaya, Caimona, and Sihuayo communities. The minority of women was bilingual (Quechua - Spanish). They all worked in the home.

The meetings lasted approximately one hour and were held in health posts. The objective of the focus groups was to know women's perspectives on health services and their ideas about how to organize women's committees in order to improve client-provider interaction, as well as to make services more culturally appropriate.

Discussion began by delving into the type of diseases that populations in these communities general suffer from. Answers allowed us to note that women know several facts of modern medicine perfectly well, for example taking a temperature, the degrees in which it indicates danger, terms for some diseases such as AIDS and cancer, the names of medicine components, such as Paracetamol or Cotrimoxazol, and the names of the most common diseases and symptoms, such as diarrhea, colds, stomach ache, toothache, cholera and fever. They said that they first treat these illnesses with herbs from their location. They only feel the need to go to health facilities when the illness does not improve with traditional treatments. Therefore they consider modern medical treatment to be a complement to traditional medicines they themselves apply. However, they feel that the biomedical treatments are frequently not too effective and generate distrust: "we also bring them here to the hospital, but they don't always know what the sickness is, we come here in vain; they give them medicines that do nothing for them, don't always cure them, and only we can cure them...”

With regards to prenatal, birth, and postpartum care, women prefer to receive midwives in their home, attend themselves, or have their partners do so: "in my house I just get sick $^{2}$, doctors poke around everywhere.” Women consider touching a pregnant woman's belly and even talking about sexual relations to be invasive procedures, whereas health providers do not see them that way. Also, women would like to be attended by doctors with experience and not by medical students during practice. Women also perceive a certain amount of discrimination related to being able to pay for the services or not: "those who have more money are better cared for, and those that don't are given nothing." Another factor they claim limits their visits to health facilities is rural work: "for women there is no time. Women have to take all their animals to graze, so they can't go to the hospital.” Finally, they consider that if the health facilities were always open, they would go, but they have on many occasions walked long distances only to find that the center is closed. In contrast, they said: "The hospital is always open and there are always personnel.”

\footnotetext{
${ }^{2}$ She uses the term "get sick" as a synonym for childbirth.
} 
Health establishments are considered not only areas for improving health, but also training places: "The best part is training," "Other communities are well-trained and we are staying behind.”

The population frequently perceives the health facility as not having the capacity to cure their sickness. On these occasions the community's curandero or traditional healer is the hope and the solution, especially when it comes to folk or magical-religious diseases that appear as the result of spells or situations that are beyond the normal ones, such as suffering, sustos or "scares" or having found the viento loco or "mad wind." Both Jampiris or K'awairis (types of healers), as well as midwives, are well-known and easily identifiable in the communities, and frequently charge for their services in kind and not with money. Care offered by a doctor and by a healer is well differentiated. The healer uses elements that are native to the locale, which is a factor of identification and trust for them, whereas the doctor uses elements that are foreign to the locale, and they do not know how they were made.

With regard to the formation of groups of women to work in the health center, they consider the key stimulus for women to go to the establishment would be training. They mentioned many subjects they would like to learn about, from knitting to literacy: "We all want to learn, we want them to come talk to us, teach us here.” They also mentioned other incentives, such as the delivery of clothing and food.

Despite the fact that the facilitator insisted that the purpose of the meetings would be that women could suggest changes in the health facilities and the way in which services were delivered (and not train them in a particular area), the women did not understand the concept. For them, the concept of giving to the health facility instead of receiving from it was alien.

\section{Interviews with Traditional Health Providers}

Researchers conducted twelve in-depth interviews with traditional healers, four of them midwives. The purpose was to know their perceptions on the practice of traditional medicine in the community and modern medical care in the health facilities, and to know their opinion about a possible linkage between the two systems. Interviews were individual and were held in the community's tambo, a space where they usually hold their meetings. In general, the perception was that answers were ample and frank.

Results showed that one of the main concerns of healers was the search for medicinal herbs and the preparation of home remedies. The diseases they attend most frequency are diarrhea, colds, head, bone and stomach aches; they also "put wawas or babies in the right place," 3 "we midwives are visited when the baby is on its side, we set it in place by massaging them.” They also heal folk or magical-religious diseases, which according to traditional healers cannot be treated in the health facilities. Their answers convey that head and bone aches, malnourishment and diarrhea are occasioned by sustos or curses:

\footnotetext{
${ }^{3}$ During pregnancy, the healers place the baby in the right position in the mother's womb through massages of different intensities.
} 
"doctors cannot cure when the soul (animo) is scared," "they do not cure because there are no medicines for those illnesses, they care for illnesses of the body."

According to these traditional doctors, the community's population is afraid to go to the health facilities, because they say they are not well treated or because they have no money: "they are afraid of the doctor, they look at us funny," "they say the medicines cost too much."

In this community there are two types of traditional physicians: midwives and healers. The latter have different specialties, among which are:

Jampiris: Use herbs and rituals

Yatiris: Wise man who makes rituals to destroy curses and spells Aysiris: More specialized yatiri who can see the future and takes disease out of the body Qaquiri: Offers frictions and massages

Llanquiri: Makes diagnoses of sickness by taking the pulse

In order for the population to request their services they need to be competent in certain areas, especially being effective in solving the problem they were consulted for. With regard to the relations with the personnel in the health facilities, they noted that a more informal type of relationship exists, limited to the exchange of comments. The closest relationships are between midwives and the health facilities, since in many cases they are the ones who suggest to the mothers they should have their baby in a health center and even accompany the woman in labor to the service. On the other hand, referral from the modern medical system to the traditional one is rare: "sometimes they send us sicknesses that they cannot heal, like sajras (bone pain) or gloria (whitish vaginal secretions in newborn girls), which we can heal.”

Traditional providers think that working with personnel in the health facilities is important, mainly for the health of the community, and they think better communication is important: "we can work by analyzing, these patients are for you and these are for me, we would both have to talk."

In terms of how they would like to organize this kind of meeting, they say it would be necessary for physicians to train them on health topics and they could also teach physicians how to help the community. They also say they would like to form a part of the health system and this means training in modern medicine: "that they teach us well so we can work together," "that they teach us more because we want to learn."

From the diagnostic study, it is apparent that traditional physicians are proud of their work, they have a great learning spirit and they consider their practice to be recognized and valued by personnel in the health facilities. What they do not understand clearly is how they can link the practice of both medicines; for them, the linkage would happen through training. 


\subsection{Changes in the Demand for Reproductive Health Services}

Table 3 compares the monthly average of services delivered in the Tinguipaya municipality in the pre- (April to December 2003) and post-intervention (April to December 2004) periods.

The most notable increases correspond to the average number of prenatal check-ups made after the fifth month of pregnancy; homebirths attended by health personnel; new condom users; new Depo-Provera users, new and continuous pill users; and new clients of any contraceptive method. The number of STI-related consultations also significantly increased. The only service indicator that decreased significantly was the average number of immunized children per month.

The table also shows that the demand for most reproductive health services is very low. For example, the monthly average of prenatal check-ups repeated in the year 2004 is 87, which means that each one of the 10 health facilities is reporting less than 9 check-ups per month. Similarly, the monthly average of continuous clients of contraceptive methods is 25 for the year 2003, and although it is greater than in 2004, the absolute number is still too low in comparison to the population of women of reproductive age (approximately 5,000 women from 15 to 49 years of age) that live in the municipality. There was no significant change in the number of clients receiving contraceptive counseling.

The absence of Pap smear tests is also noteworthy. As mentioned previously, health facilities have deficient supplies and only two of them have staff that can take the smear. With regards to care during birth, it is also striking that the number of homebirths attended by health providers is even greater than the number of births attended in the health facilities or by midwives. 
Table 3. Monthly average of services delivered in the Tinguipaya municipality during the pre-intervention (2003) and the post-intervention periods (2004)

\begin{tabular}{|c|c|c|c|}
\hline Services & $\begin{array}{l}\text { April- } \\
\text { December } 2003\end{array}$ & $\begin{array}{l}\text { April- } \\
\text { December } 2004\end{array}$ & $\begin{array}{l}\text { Statistical } \\
\text { significance }^{4}\end{array}$ \\
\hline Prenatal, new before the $5^{\text {th }}$ month & 17.6 & 17.4 & 0.998 \\
\hline Prenatal, new after the $5^{\text {th }}$ month & 26.0 & 37.6 & $0.006^{*}$ \\
\hline Prenatal, repeat & 72.1 & 87.2 & 0.870 \\
\hline Births in the health facility & 1.3 & 2.2 & 0.211 \\
\hline $\begin{array}{l}\text { Home births attended by health } \\
\text { personnel }\end{array}$ & 14.0 & 21.2 & $0.000^{*}$ \\
\hline Homebirths attended by midwife & 7.9 & 9.6 & 0.238 \\
\hline Postpartum care & 41.9 & 42.7 & 0.866 \\
\hline \multicolumn{4}{|l|}{ Family Planning } \\
\hline Contraceptive counseling & 70.3 & 67.1 & 0.651 \\
\hline Natural methods, new users & 9.1 & 9.3 & 0.936 \\
\hline Natural methods, continuous users & 8.0 & 10.6 & 0.078 \\
\hline Condom, new users & 0.7 & 2.0 & $0.028 * *$ \\
\hline Condom, continuous users & 0.8 & 1.3 & 0.147 \\
\hline Depo-Provera, new users & 8.2 & 19.4 & $0.001^{*}$ \\
\hline Depo-Provera, continuous users & 6.9 & 8.4 & 0.325 \\
\hline Pill, new users & 2.4 & 5.7 & $0.042 * *$ \\
\hline Pill, continuous users & 8.1 & 12.1 & $0.004^{*}$ \\
\hline IUD, new users & 0.1 & 0.0 & 0.332 \\
\hline IUD, continuous users & 0.7 & 0.1 & 0.133 \\
\hline Total new contraceptive users & 20.6 & 36.4 & $0.000 *$ \\
\hline Total continuous users & 24.5 & 32.5 & $0.000 *$ \\
\hline \multicolumn{4}{|l|}{ Other RH services } \\
\hline Pap smear testing & 0.0 & 0.2 & 0.332 \\
\hline Tetanus Toxoid & 237.0 & 238.0 & 0.877 \\
\hline STI-related consultations & 1.0 & 3.1 & $0.015 * *$ \\
\hline \multicolumn{4}{|l|}{$\begin{array}{l}\text { Other services for } 15 \text { to } 49 \text { year- } \\
\text { old women }\end{array}$} \\
\hline General medical consultation & 238.0 & 252.9 & 0.377 \\
\hline Dentistry consultation & 28.8 & 30.1 & 0.766 \\
\hline Yellow Fever vaccine & 56.0 & 136.4 & 0.141 \\
\hline \multicolumn{4}{|l|}{ Care for children under 5} \\
\hline Outpatient consultation - sick child & 470.9 & 553.6 & 0.820 \\
\hline Well-baby consultation & 964.7 & 1136.8 & 0.100 \\
\hline Children vaccinated & 588.2 & 407.1 & $0.037 * *$ \\
\hline Dentistry consultation & 29.6 & 30.9 & 0.820 \\
\hline
\end{tabular}

T-test for difference in means: ${ }^{*} \mathrm{p}<0.01,{ }^{* *} \mathrm{p}<0.05$. 
The following graphs show the evolution through time of some variables that differ significantly in the comparison between periods.

Graph 1. Number of homebirths attended by health personnel, pre and postintervention

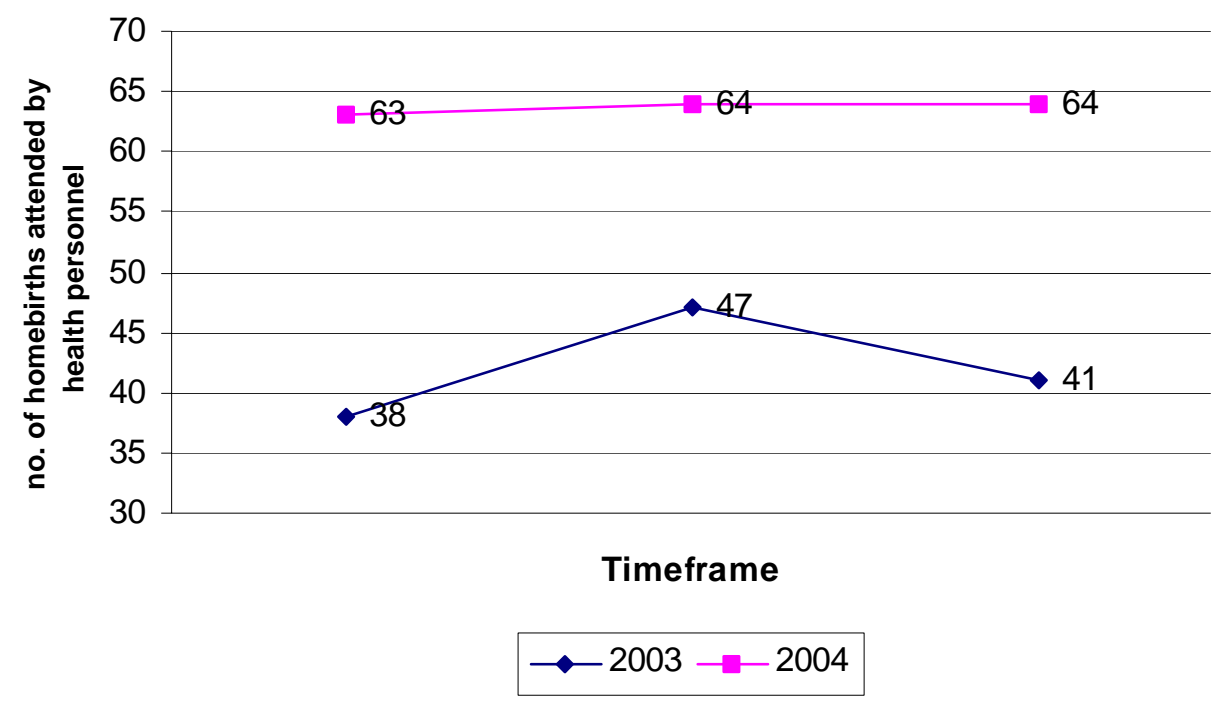

The intercultural adaptation of homebirth care by health personnel is probably one of the most valued by indigenous families, taking into account the rituals related to this event, especially clothing, feeding the mother and child, and the participation of the family in this process, which cannot be done when births take place in health facilities. Data shown in Graph 1 show a significant number of services delivered throughout the postintervention period. The promotion of homebirth and the respect for traditional practices was part of the project's intervention. However, in comparison to the number of births expected in the municipality (800 per year), the proportion of births taking place outside the health system is still large.

Graph 2 shows that in the post-intervention period there was an increase in the number of Depo-Provera users. The technical and cultural aspects of contraceptive service delivery were part of the training provided by the project. Unfortunately, results were affected by the fact that the use of the method is subject to many other external variables, mainly the availability of supplies. Although during the project there were no supplies for two months, in the year 2003 the absence of supplies was constant. Thus the statistics also reflect the functioning of the MOH's logistic system in terms of the provision of contraceptives, including Depo-Provera. 
Graph 2. Depo-Provera new users pre- and post-intervention

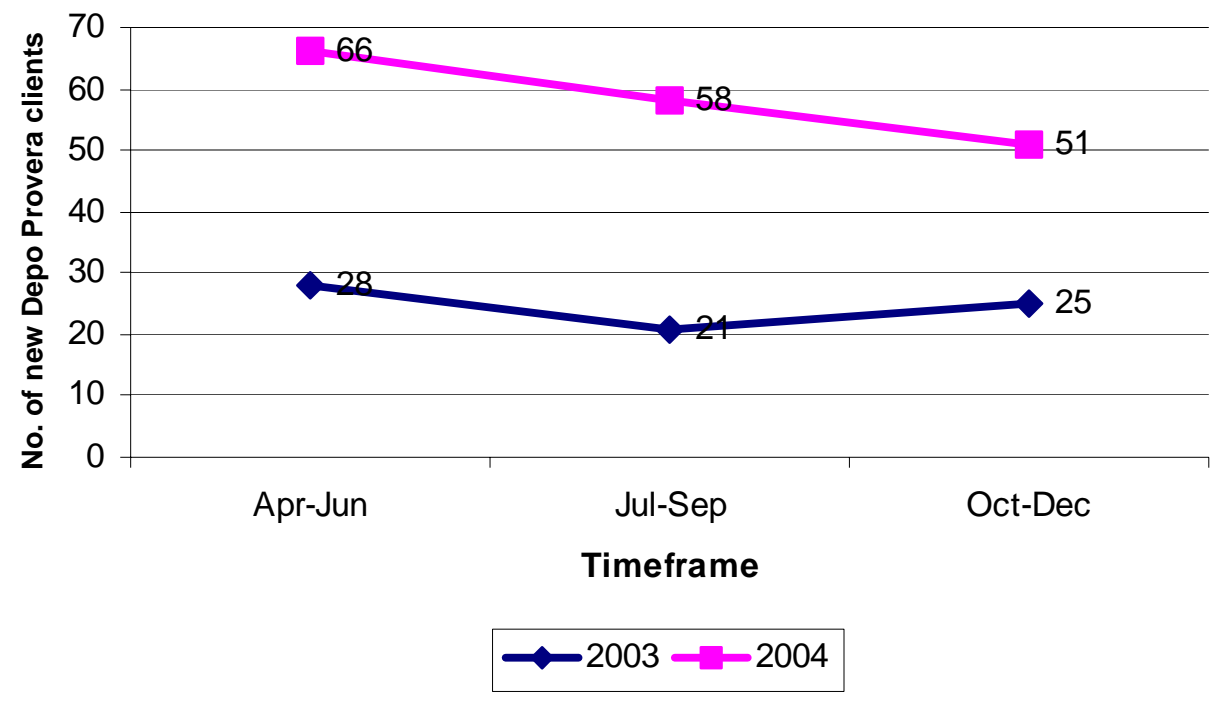

Graph 3 shows the number of new contraceptive users in 2003 and 2004. The number of injectible users increased the most, followed by users of combined oral contraceptives and, to a lesser scale, condom users. In the 10 months of project intervention (2004), no IUD users were registered, whereas in the previous year only two IUDs were inserted. The IUD is a method that is available only in two health facilities in the project area, because it has to be inserted by medical personnel. Hormonal contraceptives on the other hand are provided by nurse auxiliaries, which make up 90 percent of the health providers.

\section{Graph 3. Contraceptive Mix among New Contraceptive Users}

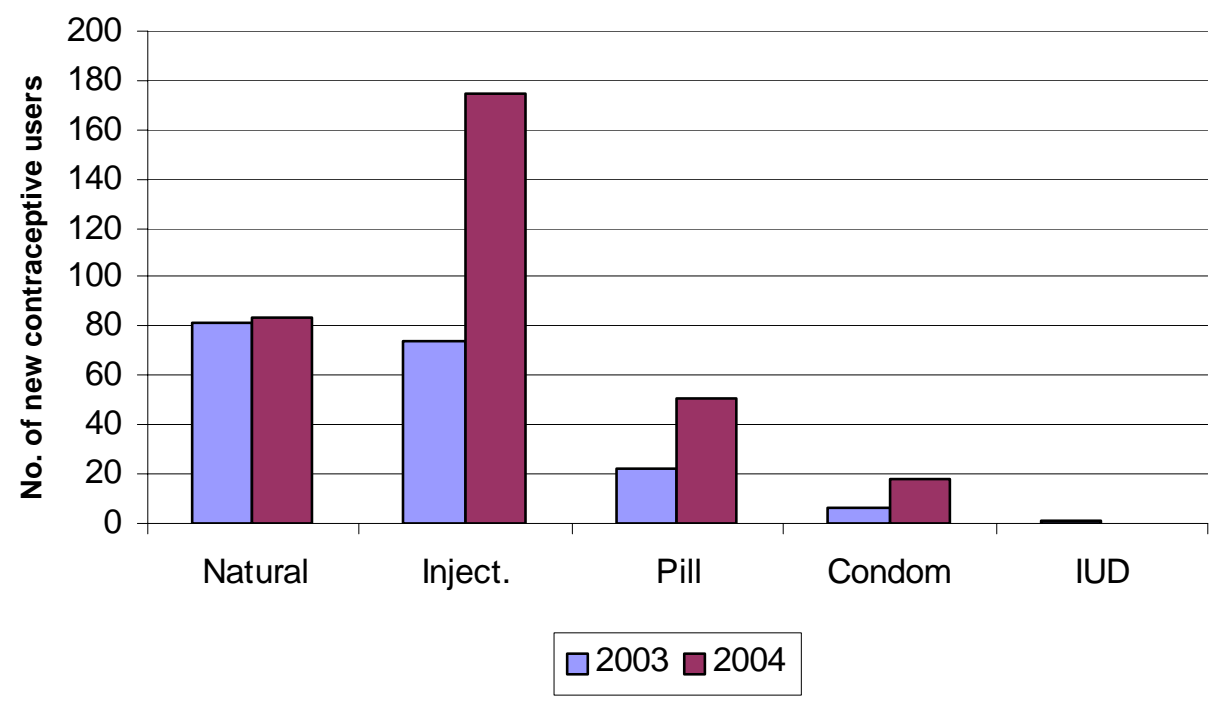




\subsection{Changes in Interpersonal Communication}

The results of 46 consultations (23 pre-intervention and 23 post-intervention) between 15 service providers and their clients are presented here. The client-provider consultations were observed and taped, exit interviews with clients were conducted, and providers in the health facilities were also interviewed.

\section{Changes in Non-Verbal Communication of Providers}

As explained in the methodology section, observers of interactions used a checklist to evaluate non-verbal communication between client and provider, coding aspects such as a welcoming expression when receiving clients, offering a seat, looking them in the eye, and creating a friendly atmosphere. Putting all the items together into one scale made it possible to estimate that before training, providers used an average of only 17.4 percent of recommended skills related to the reception of the client, whereas after training they used an average of 50 percent of the skills recommended for client reception. In terms of communication behaviors during the medical and therapeutic part of the consultation, an improvement was also noticed in the implementation of recommended skills, from 52 percent to 96 percent. When all the items in the observation guide were added up to obtain a general grade, 73 percent of providers managed to obtain high marks in nonverbal communication after training, compared to only 39 percent of providers before training.

\section{Provider Satisfaction with Job}

Health providers participating in the project were interviewed before and after the intervention, to know how they feel about their work environment and satisfaction with their job. As was the case with the other scales, responses indicative of satisfaction were assigned a one and other answers a zero. No changes in provider job satisfaction were detected, nor in their perception of work conditions as a result of the interventions. When analyzing the type of provider, we observed that in the case of nurses and nurse auxiliaries there were minor positive increases, whereas satisfaction grades between periods actually decreased in the case of doctors.

\section{Changes in Communication Content}

From the recorded client-provider consultations, the analysis revealed that there was a better balance in the communication of medical and socio-emotional contents after training. After the intervention, a greater proportion of phrases with socio-emotional content were used (52.7\%) than before the intervention (42.4\%). After training, there was also greater balance between phrases with socio-emotional content and phrases with medical content. Table 4 shows that after the intervention both clients and their husbands or people accompanying them talked more about socio-emotional issues than before training. This may be explained by the fact that trained providers made them feel more confident and stimulated their participation. 
Table 4. Percentage of Socio-Emotional Phrases Pre- and Post-Intervention

\begin{tabular}{|l|c|c|}
\hline \multirow{2}{*}{ Person } & \multicolumn{2}{|c|}{ Period } \\
\cline { 2 - 3 } & Pre-intervention (\%) & Post-intervention (\%) \\
\hline Doctor & 45.9 & 54.1 \\
\hline Nurse & 42.3 & 57.7 \\
\hline Aide & 40.6 & 59.4 \\
\hline Client & 24.2 & 75.8 \\
\hline Husband & 26.1 & 73.9 \\
\hline Other person accompanying client & 25.0 & 75.0 \\
\hline Total & 34.0 & 69.0 \\
\hline
\end{tabular}

Table 5 shows medical phrases that made a difference in the client-provider communication. The proportion of providers that counseled clients about contraceptive methods increased from 20 to 80 percent after the training; those that asked open-ended medical questions increased from 29 percent to 70 percent; and the proportion of providers that verified if the client had understood changed from 42 percent before training to 58 percent after the training.

Table 5. Percentage of providers who utilized facilitating medical phrases

\begin{tabular}{|l|c|c|}
\hline \multicolumn{1}{|c|}{ Content } & $\begin{array}{c}\text { Pre-training (\%) } \\
(\mathbf{n = 1 5 )}\end{array}$ & $\begin{array}{c}\text { Post-training (\%) } \\
(\mathbf{n = 1 5 )}\end{array}$ \\
\hline Provides FP counseling & 20 & 80 \\
\hline Asks open-ended questions & 29 & 70 \\
\hline Asks the client's opinion & 45 & 52 \\
\hline Makes sure the client has understood & 42 & 58 \\
\hline
\end{tabular}

\section{Client Satisfaction and Quality of Care}

The exit interviews conducted with clients assessed the content of the consultation, the provider's behavior, the degree to which the interaction met the clients' expectations, and their satisfaction with the service they received. To determine quality of care, responses indicative of quality were coded as one, and the rest of the answers as zero. The points were added to create a scale, and the range was divided into three grades: low, medium and high. In the pre-intervention period, 39.1 percent of clients rated the quality of care as low, compared to 22.7 percent in the post-training. The average score in the preintervention period was 52.2 percent and in the post-intervention it was 54.5 percent. Finally, in the pre-intervention period 8.7 percent of clients rated the quality of care as high, compared to 22.7 percent in the post-intervention period. In other words, client satisfaction with the care received increased significantly. 


\subsection{Changes in the Systematic Screening of Reproductive Health Services}

As part of the project, providers were trained to use a systematic screening instrument adapted from others that have been tested elsewhere, to detect unmet reproductive health needs among their clients and to provide these services during the same consultation, if possible.

Data from the taped observations revealed that doctors were more hesitant to use the systematic screening instrument, whereas nurses and nurse auxiliaries said they used it more frequently, both in health facilities as well as in communities. In the latter case, the main problem they observed during supervision visits was that they generally vaccinate children and women in the communities, but they do not have supplies with them for delivering other services. Therefore, when they applied the instrument in the community and other needed services were detected, they would ask people to visit the health center in order to get the service. The results in Table 6 present the proportion of audio-taped visits in which different reproductive health services were delivered.

Table 6. Percentage of visits in which reproductive health and infant health services were delivered, by type of service and by research period

\begin{tabular}{|l|c|c|c|c|}
\hline Services delivered & \multicolumn{2}{|c|}{ Pre-intervention } & \multicolumn{2}{c|}{ Post-intervention } \\
\hline & Number & Percentage & Number & Percentage \\
\hline Prenatal check-up & 7 & 30.4 & 2 & 8.7 \\
\hline Family Planning & 2 & 8.7 & 11 & 47.8 \\
\hline STI & 0 & 0 & 2 & 8.7 \\
\hline Postpartum check-up & 1 & 4.3 & 0 & 0 \\
\hline Pap smear & 0 & 0 & 2 & 8.7 \\
\hline $\begin{array}{l}\text { Growth and development } \\
\text { (children <5 years old) }\end{array}$ & 1 & 4.3 & 14 & 60.8 \\
\hline Immunization & 2 & 8.7 & 7 & 30.4 \\
\hline Child nutrition & 0 & 0 & 10 & 43.5 \\
\hline Sick child & 2 & 8.7 & 2 & 8.7 \\
\hline Dentistry & 0 & 0 & 5 & 21.7 \\
\hline General medicine & 8 & 34.8 & 14 & 60.9 \\
\hline \hline Total services delivered & $\mathbf{2 3}$ & & $\mathbf{6 9}$ & \\
\hline Total taped consultations & 23 & & 23 & \\
\hline $\begin{array}{l}\text { Average number of } \\
\text { services delivered per visit }\end{array}$ & $\mathbf{1}$ & & 3 & \\
\hline
\end{tabular}

The mean number of services delivered per client increased significantly, from one service per visit before the intervention to three services per visit after the intervention. This proves the usefulness of the instrument to detect client's needs and provide the services the client requires. 


\section{CONCLUSIONS}

This project was developed in a complex scenario, both from a geographical point of view (a supervision round to 10 health facilities implied an investment of 12 days) as well as from the characteristics of the municipal health network and the population it serves.

The initial diagnosis provided important information about the situation of the health service network, such as the lack of supplies and equipment, and the deficient technical skills of health providers to deliver reproductive health services, particularly contraceptive services. The existence of community health resources, such as traditional healers and midwives, was also made evident. The demand for traditional medical services is high, and it is the first option indigenous families seek for help.

Qualitative information from in-depth interviews with health providers, community women, and traditional physicians helped us identify a series of beliefs and perceptions that differ between clients and providers that act as intercultural barriers and impede their mutual understanding. But beyond these barriers, women mentioned many other barriers, such as the cost of services, having to travel to reach health facilities, the perception that physicians in health facilities are too young and inexperienced, and finally, the frustration provoked by the absence of health personnel from their work sites. Clearly, in order to increase the productivity of its health facilities, the $\mathrm{MOH}$ must incorporate processes of cultural adaptation in the context of ample quality improvement processes addressing these and other problems such as the lack of supplies and the limited technical capacity of health providers to offer reproductive health services.

Interventions to improve the quality of care and incorporate an intercultural focus had a positive significant effect on the demand for seven out of 21 reproductive health services offered in the health facilities: prenatal care, homebirths attended by health personnel, new condom users, continuous Depo-Provera users, new and continuous pill users, and STI consultations. Overall there was an increase in the monthly average of new and continuous users of any contraceptive method.

The intervention to strengthen providers' communication skills was well received and was conducted with enthusiasm by health providers. Part of the success was due to the innovative methodology, and also to the prominence given to communication of social aspects during consultations, which is usually minimized in medical training. The results of this intervention show important changes in client-provider interactions in aspects such as the warmth with which the client is received. Significant improvement was also observed in non-verbal communication and the use of socio-emotional contents in verbal communication. Lastly, greater participation was observed by the clients and their husbands. Due to its low complexity, moderate cost and acceptance, the replicability of the intervention appears to be highly feasible. 
The detection of unmet reproductive health needs and the systematic provision of services showed substantial changes between the pre- and post-intervention periods. The average number of services delivered per client increased from one to three and the change was statistically significant. The instrument for the detection of needs was used primarily by nurse auxiliaries, both in health facilities and in their community work. Due to the positive results obtained with the use of the systematic screening instrument, confirming the findings of other studies, the use of the systematic screening instrument should be promoted at a larger scale.

\section{DISSEMINATION AND USE}

The results of the initial diagnosis were presented to the Tinguipaya municipal authorities, the surveillance committee, PROSIN representatives, and all the municipality's health personnel.

During the project development, three materials or modules on intercultural relationships were created for health service providers. These modules were: a) Andean world view, which describes the traditional knowledge and practices related to reproductive health, b) culturally appropriate protocols that incorporate elements of the Andean culture in the delivery of reproductive health service, so that services respond better to cultural differences, and c) a glossary of Quechua and popular terms to help health providers establish better communication with clients, especially Quechua. The preliminary versions of these documents have been shared with $\mathrm{MOH}$ regulatory personnel, and they have expressed the intention of incorporating them as part of the national strategy for addressing the issue of cross-cultural barriers in health services.

The communication intervention was also successful, and several municipalities have requested that it be replicated. To assist in this task, there is a manual to supervise the quality of client-provider communication and supporting job-aids adapted to Bolivia's needs and cultural traditions.

The subject of integral, comprehensive health care still deserves an important role in future projects. This project showed that the use of a systematic screening instrument in health facilities and during providers' visits to rural communities promoted greater comprehensiveness of care. One of the limiting factors was the impossibility of delivering services detected in the community, since during their visits they only had on hand supplies to deliver a limited range of services. Perhaps the solution would be to create a series of five or six different instruments, one for each kind of service they take supplies for, and that in each visit they also take different supplies for a restricted set of additional services included in these job-aids.

As to creating linkages between the modern medical and traditional health systems, this is an area that should be re-examined with the idea of testing new approaches and forms of coordination. 
At the request of USAID Bolivia, a seminar to disseminate "Best Practices from Operations Research" was conducted in July 2005 with the purpose to incorporate these practices in the new health strategy for the period 2005-2009. Sixty-four participants from the MOH, JSI, PROSIN, PROCOSI and EngenderHealth (the organizations that will implement this new strategy) attended the seminar. The results of this project were presented and an expert panel discussed the implications for the new activities and prepared a list of recommendations, including the following:

- The MOH will use the protocols tested in this project to improve the quality of interpersonal communication. The interventions will be replicated in the geographic region of the new Red de Salud Project (JSI, Population Council, and Care) to improve the quality of care provided.

- The impact of incorporating the service delivery protocols with a cross-cultural perspective in the health networks will be evaluated, taking as a point of reference the results of this and other research conducted in Bolivia.

- The Red de Salud Project will provide technical assistance to conduct a situational analysis to determine the degree to which services are offered with a gender and cross-cultural perspective in 131 health networks in six Bolivian departments. 


\section{REFERENCES}

Das, N. P. et al. 2005. "Systematic screening to integrate reproductive health services in India,” FRONTIERS Final Report, Washington, DC: Population Council.

Debus M. 1995. The Handbook for Excellence in Focus Group Research. Washington, DC: Academy for Educational Development.

Family Health International (FHI). 1997. "Las mujeres de El Alto se descubren a si mismas [Women in El Alto discover themselves],” Informe final. La Paz, Bolivia: FHI, Proyecto Integral de Salud.

Foreit, James R., Ricardo Vernon, and Patricia Riveros Hamel. 2005. "Use of systematic screening to increase the provision of reproductive health services in Bolivia,"

FRONTIERS Final Report, Washington, DC: Population Council.

Foreit, Karen G. Fleischman, Karen Hardee, and Kokila Agerwal. 2002. "When does it make sense to consider integrating STI and HIV services with family planning services?" International Family Planning Perspectives 28(2): 105-107.

Gonzales, Fernando, Carlos Nava, y Susan Brems. 1991a. "Maternidad Andina [Andean motherhood].” La Paz, Bolivia: Proyecto Mother Care.

Gonzales, Fernando, Carlos Nava, y Susan Brems. 1991b. "Maternidad tradicional: conocimientos, actitudes y prácticas de las mujeres en relación al ciclo reproductivo [Traditional motherhood: Knowledge, attitudes and practices of women in relation to the reproductive cycle],” La Paz, Bolivia: Proyecto MotherCare, CIAES, and UNICEF.

Instituto Nacional de Estadística (INE) y Demographic and Health Surveys (DHS). 1998. "Encuesta Nacional de Demografía y Salud 1998 [National Demographic and Health Survey].” La Paz, Bolivia: INE y DHS.

León, Federico R. et al. 1998. "Increasing use of reproductive health services in a Peruvian clinic," in Family Planning Operations Research: A Book of Readings, eds. James R. Foreit and Tomas Frejka. New York: Population Council, pp. 239-245.

Ley del Seguro Universal Materno Ifantil, SUMI [Universal Mother and Child Insurance Law]. 2002. La Paz, Bolivia: Presidencia de la República, Honorable Congreso Nacional de la República de Bolivia, November.

Martin, Antonieta, ed. 2004. "Hablemos con confianza: Comunicación interpersonal y consejería en salud reproductiva [Let’s talk confidentially: Interpersonal communication and counseling in reproductive health].” La Paz, Bolivia: Academy for Educational Development (AED) y Centro para Programas de Comunicación, Universidad Johns Hopkins (JHU/CCP). 
Martin, Antonieta, María Elena Figueroa, y Paul Richardson. 1999. "Manual para supervisar la calidad de la comunicación interpersonal entre prestadores de servicios y usuarios [Manual for supervising the quality of interpersonal communication between service providers and clients]. México, D. F.: JHU/CCP, Proyecto de Garantía de la Calidad (URC/QAP), Instituto Mexicano del Seguro Social, Programa IMSS-Solidaridad.

Ministerio de Salud [Ministry of Health - MOH]. 2003. "Programa de Atención a la Salud de la Mujer y a la Salud Sexual y Reproductiva 2003 - 2007 Borrador. [Program for Women's Health, Sexual and Reproductive Health Care 2003-2007 Draft].” La Paz, Bolivia: Ministerio de Salud y Deportes, Dirección de desarrollo de servicios de salud.

Organización Panamericana de la Salud (OPS) [Pan American Health Organization PAHO]. 2004. "Caracterización de la exclusión en salud en Bolivia [Characterizing health exclusion in Bolivia].” La Paz, Bolivia: OPS.

OPS. 2001. “Índice de Salud Municipal 2000 [Municipal Health Index 2000].” La Paz, Bolivia: OPS, Ministerio de Salud, Federación de Asociaciones Municipales de Bolivia.

Poppe, Patricia et al. 1999. "Hablemos con confianza: Guía para acompañar el uso de videos [Let's talk confidentially: Guide to using the videos].” Baltimore, MD: JHU/CCP y AED.

Project Concern Internacional. 1997. "Proyecto de interacción de un sistema de atención primaria de salud con la comunidad en Oruro, Cochabamba y Potosí [Project for interaction between a primary health care system and the community in Oruro, Cochabamba, and Potosí].” La Paz, Bolivia: Project Concern International, Programa de Coordinación en Salud Integral (PROCOSI), U.S. Agency for International Development.

Project Concern Internacional. 1996. "Protocolos culturalmente adaptados para manejo de casos de salud reproductiva [Culturally adapted protocols for reproductive health case management]." La Paz, Bolivia: Project Concern International, Proyecto de Interacción PROCOSI.

Roter, Debra. 1997. "Coding manual for the RIAS System [Manual de codificación del sistema RIAS].” 1997. Baltimore, MD: JHU/CCP.

Roter, Debra. 1995. "The Roter Interaction Analysis System (RIAS) [Sistema de Análisis de la Interacción de Roter (RIAS)].” Baltimore, MD: JHU/CCP.

Sanogo, D. et al. 2005. "Using systematic screening to increase integration of reproductive health services delivery in Senegal,” FRONTIERS Final Report, Washington, DC: Population Council.

Unidad de Análisis de Políticas Sociales (UDAPSO) [Unit of Social and Political Análisis]. 1994. "Índices de Desarrollo Humano y otros indicadores sociales en 311 municipios de Bolivia [Human development indexes and other social indicators in 311 
municipalities in Bolivia].’La Paz, Bolivia: UDAPSO, Programa de las Naciones Unidas para el Desarrollo [United Nations Development Fund].

Velasco, Oscar. 1997a. “Interpretación de enfermedades aymará - quechua y sus equivalentes en nosología médica [Aymará-Quechua interpretations of disease and their equivalents in medical nosology].” La Paz, Bolivia: Project Concern International, Ministerio de Salud, PROCOSI, USAID.

Velasco, Oscar. 1997b. “Interacción de un sistema de atención primaria de salud con la comunidad [Interaction of a Primary Health Care System with the Community].” La Paz, Bolivia: Project Concern International, PROCOSI, y USAID.

Vernon, Ricardo and James Foreit. 1999. "How to help clients obtain more preventative reproductive health care.” International Family Planning Perspectives 25(4): 200-202. 